\title{
RESENHA
}

\section{GESTÃO E AVALIAÇÃO DA EDUCAÇÃO PÚBLICA BRASILEIRA E AS POLÍTICAS EDUCACIONAIS}

\author{
Érico Santos Pimental \\ Sandra Fernandes Leite 2
}

NEUBERT, L. F.; TAVARES, F. (Org.). Políticas Educacionais. 1. ed. Juiz de Fora: CAEd-FADEPE, 2017. v. 1. 126p.

Em 2017, a editora CAEd FADEPE da cidade de Juiz de Fora publicou o livro Políticas Educacionais, organizado por Fernando Tavares Junior e Luiz Flávio Neubert. A obra perpassa a gestão e avaliação da educação pública brasileira, tangenciando desigualdades e perspectivas educacionais a partir de um olhar sociológico, a evolução do IDEB em uma escola estadual Fluminense (RJ), o processo de implementação de um sistema de avaliação no município de Limeira-SP e o programa de Intervenção Pedagógica Alfabetização no Tempo Certo em Minas Gerais, além da inspeção escolar. Finaliza a discussão com a possibilidade de equidade e oportunidades em relação à Educação no Brasil.

O primeiro capítulo - Um olhar sociológico sobre a educação: fundamentos, desigualdades e perspectivas - de Roberta Aparecida Ribeiro Nunes, cientista social e mestre na mesma área, parte da compreensão primária de educação enquanto agente de socialização primária, de desenvolvimento social e equalizadora de oportunidades. Contrapondo essa perspectiva, suscitam-se os contextos educacionais na América Latina onde se constata sistemas educacionais fracassados, nos quais os egressos,

\footnotetext{
1 Mestrando em Educação. Programa de Pós-Graduação em Educação da Faculdade de Educação da Unicamp. E-mail: erico@cotuca.unicamp.br

2 Doutora em Educação (UNICAMP). Professora do Programa de Pós-Graduação em Educação da Faculdade de Educação da Unicamp. E-mail: sfleite@unicamp.br
} 
principalmente de redes de ensino públicas, possuem baixo desempenho em exames de proficiência aplicados.

A pesquisadora faz uma breve revisão conceitual a partir de Durkeim (1973 apud NEUBERT; TAVARES, 2017) sobre transmissão de valores e sobre socialização exercida pelas gerações adultas sobre aquelas que se preparam para a organização da vida social. Para Arroyo (2011 apud NEUBERT; TAVARES, 2017), há problemas que nos perseguem como pesadelos, como por exemplo, a qualidade da educação pública. Mas é necessário atentar-se as mudanças no conceito de qualidade no decorrer do tempo. Atualmente, o baixo desempenho dos estudantes é medido por testes de proficiência.

O campo da educação, a partir da década de 1990, foi marcado pela divulgação de resultados estatísticos pelo Instituto Nacional de Estudos e Pesquisas Educacionais (INEP). Em 1990, 91,6\% das crianças com idade entre 7 e 14 anos estavam matriculados em escolas. Em 2001 evidenciou-se um aumento no número de matrículas, já que percentual foi de 96,3\%. Brooke e Soares (2008) pesquisaram e indicaram a efetividade das Políticas Públicas Educacionais adequadas para o aprendizado.

O segundo capítulo - IDEB: o sucesso de uma escola estadual fluminense - de Karina Hernandes Neves, graduada em Letras, mestre em Gestão e Avaliação da Educação e doutoranda em Ciências Sociais, desenha-se como um estudo de caso que propôs analisar o sucesso de uma escola pública estadual do interior do estado do Rio de Janeiro com Índice de Desenvolvimento da Educação Básica (IDEB) de 7,4 e 7,7 nas edições de 2009 e 2011, uma vez que na edição de 2007 a mesma escola possuía um índice de 3.3. Registra-se a ênfase no modelo de gestão escolar com maior aproximação entre os alunos, professores e a comunidade e a instituição de colegiados na instituição.

Ressalta-se que no ano de 2011 o estado do Rio de Janeiro não atingiu a meta projetada de 3,3, resultando em 3,2. Ainda assim surpreendeu o fato de que uma escola pública do estado esteja com uma nota acima da 
média 7,7. Hipotetizou-se que o sucesso escolar havia se dado através de alguma estratégia de correção de fluxo escolar. Contudo, a progressão da escola manteve-se praticamente inalterada.

Haja vista os baixos índices do IDEB de 2007, o Governo do Rio de Janeiro incentivou a formação continuada através da Plataforma Freire, além de estabelecer parceria com renomadas instituições de formação. Cita-se também a promoção das principais alterações pedagógicas: Unificação do currículo por série e por disciplina, disponibilização do laboratório para utilização de um professor, instituiu-se o programa de monitoria para o contra turno e o cumprimento efetivo das reuniões de planejamento. Relata-se também que promoveram bonificações, como por exemplo, viagens para as turmas com melhor desempenho em avaliações internas. Para tal, arrecadou-se dinheiro a partir da organização de eventos escolares. Digno de nota é o fato de que a escola praticamente zerou a evasão escolar, obtendo em 2011 um fluxo de 99\%.

O terceiro capítulo - A Implementação do Sistema de Avaliação em Limeira (SP) - de Sandrine Cristina Ibañes Rossini, graduado em Pedagogia, especialista em Supervisão Educacional e mestre em Gestão e Avaliação da Educação Pública, analisou a implementação da política de avaliação na rede de Ensino de Limeira-SP em 2012, selecionou-se cinco escolas da rede de ensino e o objeto de pesquisa é constituído pelos gestores dessas escolas.

Apresentaram-se as condições nas quais a primeira edição do Sistema de Avaliação da Rede de Ensino Municipal (SAREM) foi instituída, em meio a estudos para instituição de um Plano de Referência Curricular com base nos Parâmetros Curriculares Nacionais - PCN. O SAREM foi concebido para avaliar, interpretar, planejar e intervir na rede de ensino, a cargo da equipe pedagógica da Secretaria Municipal de Ensino.

Destacam-se três aspectos negativos sobre o SAREM, a começar pela sobrecarga burocrática que a Secretaria Municipal de Ensino exige dos gestores escolares. O segundo aspecto é e negação do SAREM enquanto uma política de avaliação de fato, constituindo-se apenas de um caráter 
normatizador. O terceiro aspecto é sobre a pouca importância dada pelas equipes ao SAREM, ainda que o índice de acertos não atinja $70 \%$, requerendo assim a elaboração de um plano de metas. A autora referenciou Mainardes (2006 apud NEUBERT; TAVARES, 2017) e o Ciclo de Políticas, o quão por vezes quem elabora uma política não vivencia a prática da mesma, e por vezes ela pode ser aplicada de maneira alheia a planejada. Para autora, ficou evidente que os gestores atuavam com baixa liderança pedagógica, já que não dispunham da possibilidade de gerir democraticamente.

O quarto capítulo - Da Agenda à Implementação: um olhar sobre o PIP-ATC/MG - de Carla Cândida da Silva Reis, graduada em pedagogia, pós-graduada em pedagogia empresarial e mestre em Gestão e Avaliação da Educação Pública, analisou como se deu a implementação de uma política educacional pública em Minas Gerais: Programa de Intervenção Pedagógica/Alfabetização no Tempo Certo (PIP-ATC) no que se tangenciam os resultados aferidos pelo Programa de Avaliação da Alfabetização (PROALFA).

O foco da Política do PIP-ATC é de alfabetizar crianças com até oito anos de idade em todo o Estado de Minas Gerais. Essa política é norteada a partir do PROALFA, que orienta a definição de metas e ações para o aprimoramento da qualidade do ensino, embasando a instituição de políticas educacionais para uma educação com equidade e justiça social.

Os resultados do PROALFA de 2006 foram impactantes, pois $51 \%$ dos alunos avaliados com três anos de alfabetização tiveram um desempenho insatisfatório. A Secretaria de Estado da Educação promoveu workshops, fez um trabalho de campo visitando gestores e professores, agruparam-se as escolas em Escolas Estratégicas e Consolidadas, sendo a primeira com 10 ou mais alunos abaixo do nível de leitura recomendável, devendo receber, portanto, visitas semanais. Já as consolidadas, visitas quinzenais.

Em relação à Implementação de Políticas Públicas, a autora embasouse nos estudos de Mainardes (2006 apud NEUBERT; TAVARES, 2017), de Weiss 
(1998 apud NEUBERT; TAVARES, 2017), Dáscenzi e Lima (2011 apud NEUBERT; TAVARES, 2017), Souza (2003 apud NEUBERT; TAVARES, 2017) e de Najberg e Barbosa (2006 apud NEUBERT; TAVARES, 2017) sobre as diferenças entre os modelos de implementação "top-down" e "bottom-up". O primeiro modelo diz respeito à quando uma ação ou conjunto de ações é posta em prática de cima para baixo. O modelo "bottom-up" é quando a análise da política se concentra em ações dos agentes implementadores. A partir dessas definições, percebe-se que o programa PIP-ATC tem traços importantes dos dois modelos, principalmente quando a meta não é atingida e analisam-se junto com os professores as particularidades dos alunos que não estão com o nível de alfabetização recomendado.

O quinto capítulo - Inspeção Escolar e Aprendizagem no PIP-ATC - de Carmeltia dos Santos Rodrigues, mestre em Gestão e Avaliação da Educação Pública, apresenta uma pesquisa realizada sobre o papel dos inspetores escolares na implementação de uma política pública no estado de Minas Gerais: Programa de Intervenção Pedagógica - Alfabetização no Tempo Certo PIP-ATC a partir do prisma de liderança e gestão educacional respaldando-se em Lück (2009 apud NEUBERT; TAVARES, 2017). O PIP-ATC foi criado após a divulgação de resultados de avaliações externas. A hipótese era de que os inspetores não se consideravam profissionais da educação, eximindo-se da responsabilidade de realizar análises pedagógicas que contribuíssem para a melhoria do desempenho dos estudantes no PROALFA.

Contudo, a Secretaria de Estado da Educação de Minas Gerais propôs um novo enfoque da inspeção escolar, ora atendendo a gestão administrativa, ora a gestão pedagógica, resultando em uma manifestação formal de 600 inspetores que assinaram a "Carta das Roças Novas", indagando quais as reais contribuições os inspetores escolares podem prestar para o aperfeiçoamento das políticas educacionais a cargo do estado. Ressalta-se que a suposição inicial de que os inspetores resistiam a analisar questões de cunho pedagógico não se confirmou, mas constatou-se 
que o enfoque a gestão pedagógica acumula-se com as demais atividades inerentes a rotina escolar determinada legalmente.

O sexto e o último capítulo - O Brasil e sua Educação: sociedade, equidade e oportunidades - de Fernando Tavares Júnior, professor de Ciências Humanas da Universidade Federal de Juiz de Fora, apresenta hipóteses e analisa argumentos em relação aos indicadores de avaliações que coloca os Sistemas de Ensino brasileiro entre os mais ineficientes, excludentes e improdutivos do mundo. Apresenta-se um breve contexto histórico sobre a improdutividade escolar, perpassando Anísio Teixeira e Gaudêncio Frigotto, estabelecendo comparação com os Sistemas Educacionais Asiáticos. Convidam-se os leitores a repensar a produção do fracasso escolar brasileiro que tem cor, classe e renda.

Tavares Júnior convida seus interlocutores a repensarem alguns graves limites impeditivos ao sucesso escolar: a naturalização das reprovações, a falta de uma Base Nacional Comum, o que realmente é estar bem alfabetizado, as expectativas em relação à alfabetização que, atualmente, são baixas, prevendo que algumas crianças ainda não estejam alfabetizadas, a formação de professores, além do fato de as escolas possuírem cada vez menos poder, autonomia e capacidade gestora.

Os artigos e ensaios que compõe a obra Políticas Educacionais possuem uma coesão no encadeamento de conceitos e propostas de discussão: o primeiro apresentou o conceito de qualidade na educação, enquanto o segundo referenciou o Índice de Desenvolvimento da Educação Básica - IDEB enquanto um referencial da qualidade educacional brasileira. A partir dessa discussão, o terceiro quarto e o quinto capítulo apresentaram distintas experiências na elaboração e implementação de políticas públicas de avaliação de sistemas de ensino de municípios da região sudeste do Brasil. O sexto capítulo articulou todos os demais em torno do cerne da questão do que é a escola tradicional brasileira.

Recebida em: Maio de 2017 Aprovada em: Outubro de 2017 